\title{
Before and During the Pandemic: Alcohol Consumption and Related Problems in Argentina
}

\author{
Karina Conde $^{1 \text { a y b }}{ }^{\mathbb{C}}$, Paula Victoria Gimenez ${ }^{\text {a y b }}{ }^{\circledR}$, Tomás \\ Salomón ${ }^{\text {a y b }}{ }^{\mathbb{D}}$, Raquel Inés Peltzer ${ }^{\text {a y b }}{ }^{\mathbb{D}}$, Sebastián Laspiur ${ }^{\mathfrak{C}} \mathbb{C}, \&$ \\ Mariana Cremonte a y bid $2 \& 3$
}

\begin{tabular}{l} 
Consejo Nacional de Investigaciones Científicas y Técnicas de Argentina ${ }^{\mathrm{a}}$; \\
Universidad Nacional de Mar del Plata, Mar del Plata, Argentina $^{\mathrm{b}}$; \\
Organización Panamericana de la Salud. Buenos Aires, Argentina $^{\mathrm{c}}$ \\
\hline
\end{tabular} ABSTRACT
The impact of the COVID-19 pandemic and isolation measures on alcohol consumption remains unknown
among Latin-American countries. This paper characterizes differences in alcohol consumption and related
problems before and during the pandemic among Argentinians from different genders, age groups, income
levels, and behaviors regarding the acquisition of alcoholic beverages. Through an online survey 1446
participants were assessed regarding four alcohol consumption dimensions (frequency, quantity, heavy
episodic drinking -HED- and alcohol-related problems) three months prior and after the first cases in the
country and subsequent lockdown measures. Overall, participants reported small reductions for usual
consumption and moderate ones for HED and related problems. As expected, very high reductions were
found for those underage (14 to 18 years), and young adults (19 to 24 years). Those who had an increase in
income after the pandemic did not report changes in consumption, while those whose income remained
equal or lowered reported reductions. Those who did not report special behaviors to acquire alcohol (e.g.
pre-stocking) informed decreases in consumption compared to those who did. This study provides new
evidence on the impact of environmental factors in public health, suggesting restricted access to alcohol
generates a significant decrease in alcohol consumption and related problems. Keywords

COVID-19; pandemic; alcohol; problems; consumption; Argentina

\section{RESUMEN}

El impacto de la pandemia por COVID-19 y el aislamiento sobre el consumo de alcohol en Latinoamérica es aún desconocido. Este artículo caracteriza los cambios en el consumo de alcohol y problemas asociados antes y durante la pandemia, diferenciando según género, edad, ingresos y comportamientos de compra de alcohol. 1446 argentinos completaron una encuesta online sobre cuatro dimensiones del consumo de alcohol (frecuencia, cantidad, consumo excesivo episódico -CEE- y problemas asociados) tres meses antes y después del comienzo del aislamiento. Se registraron pequeñas reducciones en el consumo de alcohol, y moderadas en el CEE y los problemas asociados. Se encontraron grandes reducciones del consumo en menores (14 a 18 años) y jóvenes (19 a 24 años). Quienes aumentaron sus ingresos durante la pandemia no reportaron cambios, mientras que quienes mantuvieron o redujeron sus ingresos consumieron menos. Quienes no reportaron comportamientos especiales en la compra de bebidas alcohólicas (por ejemplo, acopiar antes de las medidas de aislamiento) informaron reducciones en el consumo comparado con quienes sí lo hicieron. Este estudio aporta evidencia acerca del impacto de los factores ambientales sobre la salud pública, sugiriendo que restringir el acceso al alcohol genera una reducción significativa del consumo y los problemas asociados.

Palabras Claves

COVID-19; pandemia; alcohol; problemas; consumo; Argentina.

\footnotetext{
1 Correspondence about this article should be addressed to Karina Conde: $\underline{\text { kconde@mdp.edu.ar }}$

2 Conflicts of Interest: The authors declare that the research was conducted in the absence of any commercial or financial relationships that could be construed as a potential conflict of interest. 3 Instituto de Psicología Básica, Aplicada y Tecnología (IPSIBAT - UNMdP - CONICET)
} 


\section{ANTES Y DURANTE LA PANDEMIA: CONSUMO DE ALCOHOL Y PROBLEMAS ASOCIADOS EN ARGENTINA}

\section{Introduction}

The COVID-19 pandemic changed almost every life area in people all over the world. Different countries coped with this new threat with a wide variety of approaches and policies. In Argentina, the main strategy promoted by the national government consisted of a system of five phases of strict social isolation (lockdown), beginning on March, 20th, when the country had 158 active cases and 3 deaths (Ministerio de Salud de la Nación [MSN], 2020a). This first phase allowed only essential workers (e.g.: physicians, nurses, basic supplies providers, security forces) to leave their homes. Since then, different provinces and departments have advanced to other phases, depending on the number of registered cases and the case duplication time (MSN, 2020b). But despite the strict policies taken by the national government, the pandemic's impact in Argentina is far from being over. On July 22th, the country registered its highest number of cases in one day (5872) and reached a total of 2588 deaths since the pandemic started (MSN, 2020c).

Alcohol consumption has been a worldwide health problem even before the COVID-19 pandemic, being an important risk factor for death and disabilities. In Argentina, alcohol consumption is highly accepted and widespread among the population. Nearly 9 liters of pure alcohol are consumed per person per year (World Health Organization [WHO], 2018).

Although the impact of the COVID-19 pandemic and isolation on alcohol consumption remains unknown, experts urged to investigate and monitor this issue (García-Álvarez et al., 2020; Rehm et al., 2020). Because alcohol consumption has been associated with respiratory diseases, such as respiratory distress syndrome or pneumonia (Thakur et al., 2009), it is considered a risk factor for COVID-19 (Saengow et al., 2020). Furthermore, the immunologic system is depressed by alcohol (Szabo \& Saha, 2015), increasing the chances of a worse outcome once infected (Testino, 2020). Additionally, those with an alcohol use disorder, besides a higher risk of infection due to a depressed immune system could also present underlying high-risk comorbidities (Schuckit, 2009). Even more, they could face extraordinary obstacles to reach or remain abstinent, due to the pandemic impact on mental health and rehab services (e.g. temporary suspension of twelve step groups meetings). Medical and/or psychological support could be harder to 
obtain because health resources are focused on COVID-19 patients; rehab institutions and support groups could be inactive due to the isolation measures (The Lancet, 2020a), and that scenario could translate into an overload of public health services.

Little is known about the possible changes in alcohol consumption during the pandemic, since, to our best knowledge very few empirical studies have been conducted. In China, levels of harmful use and dependence increased during the pandemic, especially among men (Ahmed, et al., 2020). In the USA, psychological distress due to the COVID19 pandemic was positively associated with drinking, especially among women, as they would use alcohol to cope with this stressful situation more than men (Rodriguez et al., 2020). Similar results have been found in Poland, where people who drank more alcohol also showed worse strategies to cope with stress (Chodkiewicz et al., 2020). Moreover, in Australia people who adversely changed their alcohol consumption during the pandemic also reported higher levels of anxiety, depression and stress (Stanton et al., 2020). In this line, a study from Canada showed that diverse stressors during the pandemic (e.g. social isolation, having children at home or income loss) predicted higher alcohol consumption (Wardell et al., 2020).

As those studies prove, changes in consumption due to this universal stressor may differ among different groups and situations. On the one hand, adolescents and young adults drinking may decrease, since social meetings and other events associated with youth drinking are restricted or forbidden. For example, a study from Poland showed that people who decreased their alcohol consumption during the pandemic were more likely to be younger (Chodkiewicz et al., 2020). Similarly, a study performed with Canadian adolescents showed a significant decrease in binge drinking during the pandemic (Dumas, Ellis, \& Litt, 2020). On the other hand, the pandemic and the isolation have affected the labor situation and income level among many, also retraining access to alcohol. This last group might have followed one of two possible paths: either reduced their consumption due to lack of economic resources or increased it due to an additional source of psychological distress (Rehm, et al., 2020).

At this time, the impact of COVID-19 is growing in Latin America as the number of cases continues to increase, leading experts to consider some countries of the region as the new hot spots of the pandemic (Dyer, 2020). This scenario highlights the need to assess the impact of the pandemic and social distancing/isolation on alcohol consumption. Thus, this paper characterizes differences in alcohol consumption and related problems before and during the pandemic (three months prior and three months after the first cases 
were reported and lockdown measures started) among Argentinians from different genders, age groups, and income levels.

\section{Method}

\section{Participants}

Data was collected from a non-probabilistic, convenience sample. More information about data collection can be found in the procedure. Of the 2373 people who started the survey, 2127 (90\%) gave their consent to participate. Of them, 305 (14\%) left mostly uncompleted questionnaires; as drinking in the last 12 months was an inclusion criterion, $259(12 \%)$ abstainers were excluded, and an additional 177 responses (8\%) were deleted due to inconsistencies (e.g. reporting drinking more than 100 alcohol standard units per occasion), making the final sample $\mathrm{N}=1446$. The majority came from Buenos Aires province (55\%), followed by Cordoba province $(8 \%)$, the autonomous city of Buenos Aires (7\%), Santa Fe province (6\%), Rio Negro province (4\%), Mendoza and Entre Rios provinces (3\% each), Neuquén and Chubut provinces (2\% each), and finally Catamarca, Chaco, Corrientes, Formosa, Jujuy, La Pampa, La Rioja, Misiones, Salta, San Juan, San Luis, Santa Cruz, Santiago del Estero, Tierra del Fuego and Tucumán provinces, (1\% or less each). Descriptive data is presented in Table 1.

\section{Materials}

Alcohol use: Quantity and Frequency of usual alcohol use and frequency of Heavy Episodic Drinking. We asked about the usual quantity of drinking in standard units (any beverage with about 12 grams of pure alcohol) (Cremonte, Cherpitel, et al., 2010). Frequency of drinking and heavy episodic drinking (HED) were assessed as in the Alcohol Use Disorder Identification Test (AUDIT) (Babor et al., 2001). This instrument was created by the World Health Organization and showed good psychometric performance in our country (Conde, et al., 2018; Cremonte, Ledesma, et al., 2010). The answer scale for the frequency of drinking was: never (0), less than once a month (1), 24 times a month (2), 2-3 times a week (3), 4 or more a week (4). For excessive episodic drinking, we asked the frequency in which the person had more than 5/4 drinks (male/female): never (0), less than monthly (1), monthly (2), weekly (3), daily or almost daily (4). 
Table 1.

Descriptive data, general population, $N=1446$.

\begin{tabular}{|c|c|c|c|}
\hline & $\mathrm{n}(\%)$ & $\mathrm{M}(\mathrm{DS})$ & IC95\% \\
\hline \multicolumn{4}{|l|}{ Gender } \\
\hline Female & $1107(77)$ & & $74-79$ \\
\hline Male & $325(22)$ & & $20-25$ \\
\hline Transgender/Non-binary & $14(1)$ & & \\
\hline Age & & $36.01(13.46)$ & $35.34-36.75$ \\
\hline \multicolumn{4}{|l|}{ Changes in Income } \\
\hline Higher & $64(4)$ & & $3-5$ \\
\hline Equal & $729(50)$ & & $48-53$ \\
\hline Lower & 634(44) & & $41-46$ \\
\hline \multicolumn{4}{|c|}{ Alcohol related purchases } \\
\hline Pre-stocking & 449(31) & & $28-33$ \\
\hline Delivery & $250(17)$ & & $15-19$ \\
\hline In store & $556(38)$ & & $36-41$ \\
\hline \multicolumn{4}{|c|}{$\begin{array}{l}\text { Alcohol use and related } \\
\text { problems before the pandemic }\end{array}$} \\
\hline Quantity & & $2.53(2.71)$ & $2.4-.2 .68$ \\
\hline \multicolumn{4}{|l|}{ Frequency } \\
\hline Less than once a month & 263(18) & & $16-20$ \\
\hline 2-4 times a month & $550(38)$ & & $35-40$ \\
\hline 2-3 times a week & $447(31)$ & & $28-33$ \\
\hline 4 or more a week & 186(13) & & $11-15$ \\
\hline \multicolumn{4}{|c|}{ Heavy Episodic Drinking } \\
\hline Never & 42 & & $40-45$ \\
\hline Less than monthly & 23 & & $21-25$ \\
\hline Monthly & 14 & & $12-16$ \\
\hline Weekly & 18 & & $16-20$ \\
\hline Daily or almost daily & 2 & & $1-3$ \\
\hline Alcohol related problems & & $5.75(4.62)$ & $5.51-5.99$ \\
\hline \multicolumn{4}{|c|}{$\begin{array}{l}\text { Alcohol use and related } \\
\text { problems after the pandemic }\end{array}$} \\
\hline Quantity & & $2.10(2.28)$ & $1.99-2.23$ \\
\hline \multicolumn{4}{|l|}{ Frequency } \\
\hline Never & $99(7)$ & & $5-8$ \\
\hline Less than once a month & $323(22)$ & & $20-24$ \\
\hline 2-4 times a month & $421(29)$ & & $27-31$ \\
\hline 2-3 times a week & $340(23)$ & & $21-26$ \\
\hline 4 or more a week & 263(18) & & $16-20$ \\
\hline \multicolumn{4}{|c|}{ Heavy Episodic Drinking } \\
\hline Never & $893(61)$ & & $59-64$ \\
\hline Less than monthly & $240(17)$ & & $15-18$ \\
\hline Monthly & $107(7)$ & & $6-9$ \\
\hline Weekly & 166(11) & & $10-13$ \\
\hline Daily or almost daily & $45(3)$ & & $2-4$ \\
\hline Alcohol related problems & & $4.42(4.38)$ & $4.19-4.65$ \\
\hline
\end{tabular}
Note. $\mathrm{CI}=$ Confidence Interval.

Alcohol related problems. They were measured with the AUDIT items assessing alcohol related problems, sometimes referred to as the AUDIT-P (Johnson et al, 2020). Those 7 items evaluate alcohol related problems, with total scores between 0 and 28 . 
Socio-demographic characteristics. We inquired about sex (women/man), gender (female/male/non-binary), age (in years), and changes in income during the lockdown (higher, equal, or lower).

Alcohol related purchases. We asked if the participant had stocked up alcoholic beverages before the lockdown started (yes/no), had used online delivery systems to purchase alcoholic beverages during lockdown (yes/no), or if he/she had violated the measures to acquire alcoholic beverages (yes/no).

\section{Procedure}

Data collection began on June 30th and was carried out until July 20th, 2020. In this cross-sectional study we measured alcohol use and related problems in two periods: the three months prior and after the first confirmed cases in Argentina, and subsequent lockdown. Specifically, participants were asked: "Next, we are going to ask you about your consumption of alcoholic beverages during the 3 months prior to the beginning of isolation (between 20-12-2019 and 19-03-2020)". The following instruction was: "Now, we are going to ask you about your consumption of alcoholic beverages since the beginning of the isolation (20-03-2020) until today or during the time you were isolated".

Data was collected online using the LimeSurvey platform. A link to the questionnaire was sent through different social networks (Facebook, Instagram, and Twitter). Completing the survey took approximately 15 minutes. People 14 years of age and older were invited to participate. Before accessing the questionnaire, participants had to complete a captcha and provide informed consent. The voluntary, anonymous, confidential, and unrewarded status of participation was explained. Besides, contact information regarding the project team and services tending to alcohol use problems were provided.

\section{Data Analysis}

We performed descriptive and group difference analyses with those who had had at least one drink in the past twelve months. As the normality (estimated by Shapiro-Wilk test on residuals, $\mathrm{p}>.05$ ) and homoscedasticity (estimated by Bartlett's test, p>.05) assumptions for ANOVA were violated, we used Kruskal-Wallis $\mathrm{H}$ to establish differences in consumption and related problems in two time frames: 1) before and 2) during the COVID-19's pandemic. Analyses comparing the before and during pandemic 
consumption were replicated with the sample segmented by gender, age group, changes in income, and alcoholic beverages purchase behaviors (stocking before lockdown, use of an online delivery system to purchase, or violating lockdown to acquire). Age groups were classified according to the country's illegal age of purchase and consumption (18 years, including adolescents of this age, that can legally purchase alcohol), age until alcohol sensitive brain regions develop (24 years), early adulthood (25-30 years), adulthood (31-60 years), and elderly (more than 60 years). We estimated changes in percentages by calculating the percentage in which each participant reduced/increased her/his alcohol use or alcohol use problems. For each participant, we subtracted the quantity, frequency, HED and alcohol related problems during the pandemic to the same characteristics before the pandemic. Then, we estimated the percentage of such differences regarding the quantity, frequency, HED and alcohol related problems before the pandemic. Later, we performed descriptive analysis (mean of percentage) by the groups. We used SPSS 19 version for the tests (IBM Corp., 2010). To estimate the effect size we calculated Cohen's $d$ with an online calculator (www.psychometrica.de/effect_size.html). Traditionally, size effects are considered: small $\mathrm{d}=.20$, medium $\mathrm{d}=.50$, and large $\mathrm{d}=.80$.

\section{Ethical considerations}

The study was conducted following the ethical standards required in Argentina, the Universal Declaration of Ethical Principles for Psychologists, the International Ethical Guidelines for Biomedical Research Involving Human Subjects, and the declarations of the Interamerican Society of Psychology regarding ethical behavior. The project was approved by the Ethics Committee of the Universidad Nacional de Mar del Plata, Argentina.

\section{Results}

\section{Changes on alcohol consumption before and during the pandemic for total sample}

For the total sample significant reductions were found in the four consumption dimensions (quantity, frequency, HED, and related problems) before and during the pandemic. We observed medium size effects in quantity $[\mathrm{H}(\mathrm{df})=50.30(1), \mathrm{p}=.001$, Cohen's $\mathrm{d}=.26]$ and small in frequency $[\mathrm{H}(\mathrm{df})=8.43(1), \mathrm{p}=.004$, Cohen's $\mathrm{d}=.10]$ and HED $[\mathrm{H}(\mathrm{df})=94.34(1), \mathrm{p}=.001$, Cohen's $\mathrm{d}=.36]$. A medium size effect was found in alcohol 
related problems $\mathrm{H}(\mathrm{df})=105.58(1), \mathrm{p}=.001$, Cohen's $\mathrm{d}=.39$. The mean reduction on each variable was: quantity $12 \%$, frequency $6 \%$, HED $30 \%$, and alcohol related problems $49 \%$ (not shown in tables).

Table 2 shows the Kruskal-Wallis H test and Cohen's d coefficients to assess changes in the four consumption dimensions (quantity, frequency, HED, and related problems) before and during the pandemic, for each gender, age, changes in income, and purchasing behavior groups.

Table 2

Differences in alcohol consumption and related problems before and during the COVID19 pandemic among groups, general population, $N=1446$.

\begin{tabular}{|c|c|c|c|c|c|c|c|c|}
\hline & \multicolumn{2}{|c|}{ Quantity } & \multicolumn{2}{|c|}{ Frequency } & \multicolumn{2}{|c|}{$\begin{array}{l}\text { Heavy Episodic } \\
\text { Drinking }\end{array}$} & \multicolumn{2}{|c|}{$\begin{array}{l}\text { Alcohol related } \\
\text { problems }\end{array}$} \\
\hline & $\mathrm{H}(d f)$ & $d$ & $\mathrm{H}(d f)$ & $d$ & $\mathrm{H}(d f)$ & $d$ & $\mathrm{H}(d f)$ & $d$ \\
\hline \multicolumn{9}{|l|}{ Gender } \\
\hline Female $(n=1107)$ & $47.83(1)^{* *}$ & .29 & $6.38(1)^{*}$ & .10 & $70.63(1)^{* *}$ & .36 & $70.46(1)^{* *}$ & .36 \\
\hline Male $(n=325)$ & $5.94(1)^{*}$ & .17 & $1.74(1)$ & .07 & $22.12(1)^{* *}$ & .37 & $31.92(1)^{* *}$ & .45 \\
\hline $\begin{array}{l}\text { Transgender/Non- } \\
\text { binary }(n=14)\end{array}$ & $.03(1)$ & .39 & $.46(1)$ & .29 & $.46(1)$ & .29 & $2.4(1)$ & .48 \\
\hline Age in years & & & & & & & & \\
\hline $14-18(n=89)$ & $23.92(1)^{* *}$ & .77 & $18.08(1)^{* *}$ & .66 & $27.4(1)^{* *}$ & .84 & $42.13(1)^{* *}$ & 1.1 \\
\hline $19-24(n=215)$ & $33.07(1)^{* *}$ & .56 & $22.2(1)^{* *}$ & .46 & $61.43(1)^{* *}$ & .80 & $59.48(1)^{* *}$ & .79 \\
\hline $25-30(n=278)$ & $16.54(1)^{* *}$ & .34 & $7.49(1)^{*}$ & .22 & $30.18(1)^{* *}$ & .47 & $14.65(1)^{* *}$ & .32 \\
\hline $31-60(n=743)$ & $3.6(1)$ & .08 & $1.73(1)$ & .04 & $11.97(1)^{* *}$ & .17 & $22.18(1)^{* *}$ & .24 \\
\hline $\begin{array}{l}61 \text { or more } \\
(\mathrm{n}=81)\end{array}$ & $.06(1)$ & .15 & $.01(1)$ & .16 & $.95(1)$ & .03 & $2.19(1)$ & .17 \\
\hline \multicolumn{9}{|l|}{$\begin{array}{l}\text { Changes in } \\
\text { Income }\end{array}$} \\
\hline Higher $(n=64)$ & $2.93(1)$ & .25 & $1.72(1)$ & .15 & $5.35(1)^{*}$ & .38 & $9.15(1)^{* *}$ & .52 \\
\hline Equal (n=729) & $29.47(1)^{* *}$ & .28 & 2.61(1) & .07 & $56.7(1)^{* *}$ & .4 & $55.71(1)^{* *}$ & .39 \\
\hline Lower $(\mathrm{n}=634)$ & $18.99(1)^{* *}$ & .24 & $4.22(1)^{*}$ & .10 & $30.41(1)^{* *}$ & .31 & $41.06(1)^{* *}$ & .36 \\
\hline \multicolumn{9}{|l|}{$\begin{array}{c}\text { Alcohol related } \\
\text { purchases }\end{array}$} \\
\hline $\begin{array}{l}\text { Pre-stocking YES } \\
(\mathrm{n}=449)\end{array}$ & $.72(1)$ & .03 & $29.63(1)^{* *}$ & .36 & $2.99(1)$ & .09 & $11.30(1)^{* *}$ & .21 \\
\hline $\begin{array}{l}\text { Pre-stocking NO } \\
(\mathrm{n}=997)\end{array}$ & $88.04(1)^{* *}$ & .43 & $50.74(1)^{* *}$ & .32 & $122.11(1)^{* *}$ & .51 & $117.39(1)^{* * *}$ & .5 \\
\hline $\begin{array}{l}\text { Delivery YES } \\
(\mathrm{n}=250)\end{array}$ & $.15(1)$ & .08 & $3.69(1)$ & .15 & $6.91(1)^{* *}$ & .22 & $16.21(1)^{* *}$ & .35 \\
\hline $\begin{array}{l}\text { Delivery NO } \\
(\mathrm{n}=1196)\end{array}$ & $59.72(1)^{* *}$ & .32 & $16.96(1)^{* *}$ & .16 & $93.73(1)^{* *}$ & .40 & $90.49(1)^{* *}$ & .39 \\
\hline $\begin{array}{l}\text { In store YES } \\
(\mathrm{n}=556)\end{array}$ & $4.41(1)^{*}$ & .11 & $.47(1)$ & .04 & $23.44(1)^{* *}$ & .28 & $34.52(1)^{* *}$ & .35 \\
\hline $\begin{array}{l}\text { In store NO } \\
(\mathrm{n}=890)\end{array}$ & $59.90(1)^{* *}$ & .37 & $18.87(1)^{* *}$ & .20 & $86.22(1)^{* *}$ & .45 & $82.39(1)^{* *}$ & .44 \\
\hline
\end{tabular}


Changes on alcohol consumption before and during the pandemic considering gender

For females, reductions were found, as follows: quantity (12\%), frequency (5\%), HED (29\%), and alcohol related problems (44\%), with mostly medium size effects. For males, statistically significant reductions were found in quantity (14\%, small size effect), $\operatorname{HED}(32 \%$, medium size effect), and alcohol related problems (64\%, medium size effect). Alcohol consumption and related problems did not differ before and during the pandemic for transgender/non-binary participants.

\section{Changes on alcohol consumption during the pandemic considering age}

Alcohol consumption and related problems decreased markedly during the pandemic/lockdown among those 30 or younger; with very large size effects, quantity, frequency, HED, and related problems were $89 \%, 42 \%, 71 \%$, and $143 \%$ lower in those aged 15-18 years. For those between 19-24 years the mean reduction was quantity $41 \%$, frequency 18\%, HED 67\%, and alcohol related problems 122\%; and for those between 25-30 years the mean reduction was quantity $10 \%$, frequency $10 \%$, HED $40 \%$ and alcohol related problems $38 \%$. Participants between 31 and 60 years reported reductions only in HED (11\%) and alcohol related problems (23\%), with small size effects.

\section{Changes on alcohol consumption during the pandemic considering changes in income}

Participants whose income increased during the pandemic/lockdown did not report changes in quantity and frequency of drinking, however, HED (34\%) and alcohol related problems $(80 \%)$ diminished; those participants whose income remained equal reported decreases in quantity (10\%), HED (32\%) and alcohol related problems (50\%), while those whose income lowered diminished all alcohol use dimensions (quantity 12\%, frequency $5 \%$, HED 32\%) and alcohol related problems (45\%). Size effects were mostly medium.

\section{Changes during the pandemic considering purchasing behavior}

Regarding alcohol related purchases, the frequency of alcohol consumption was higher $(21 \%)$ during the pandemic/lockdown among those who stocked up alcoholic beverages, but alcohol related problems lowered (25\%). Among those who used an online delivery system to purchase alcohol, HED (20\%) and alcohol related problems $(50 \%)$ decreased. While those who reported violating the lockdown to purchase alcohol reported 
an increase in quantity (1\%), but a decrease in HED (24\%) and alcohol related problems $(51 \%)$. Diminished consumption was found among those who did not purchase alcoholic beverages either through stocking (quantity 26\%, frequency 18\%, HED 40\%, and alcohol related problems $60 \%$ ), or the use of an alcohol delivery system, (quantity 17\%, frequency $9 \%$, HED $32 \%$, and alcohol related problems $49 \%$ ) or violated the lockdown to purchase (quantity 19\%, frequency 12\%, HED 33\%, and alcohol-related problems 47\%). Here again, size effects were mostly medium, with the exception of frequency of alcohol consumption in those who did not use delivery or bought in stores, where it was small.

\section{Discussion}

Overall, reductions were found in the whole sample for the four consumption dimensions, usual quantity and frequency of drinking, HED, and alcohol related problems. Findings for the whole sample, and in general for most subgroups, indicate small to null decreases in frequency of consumption, followed by moderate diminutions in quantity of consumption, and moderate to large reductions for HED and alcohol related-problems. Although the international literature has shown HED behavior to be related to social gatherings and outings (both prohibited with the social isolation measures) (Piontek et al., 2013), this pandemic/lockdown is an excellent opportunity to bring into light new evidence about the effect of social environment on drinking behaviors and problems. Besides important reductions in HED we also observed important decreases in alcohol related problems. Such diminishing of the negative consequences of drinking could be attributed in the first place, to the quantity and frequency decreases (i.e. people drinking less, and less often). Secondly, there were large reductions in HED, which in turn is strongly related to a wide array of other risky behaviors, such as drinking and driving (Quinn, \& Fromme, 2012) or harmful consequences, like blackouts (Conde et al., 2016). Furthermore, some environmental factors that could expand drinkers' vulnerability, or result in cumulative risk exposures, were also modified during the pandemic/lockdown; for instance, lack or reductions in mobility could have contributed to reducing alcohol related crashes and injuries.

Results indicate decreases in consumption among women were similar to those of the whole sample, unsurprisingly since a large proportion of our sample was female. Males reported a similar decrease in quantity than females, but no changes in frequency. However, males had greater reductions than females on HED and alcohol related problems. These results could be due to males' consumption patterns before the 
pandemic/lockdown. Although the gender gap is diminishing among youth in Argentina (MSN, 2019), traditional gender differences are still observed, with males exhibiting a higher frequency of risky drinking, like HED, and harmful consequences (Erol \& Karpyak, 2015; Secretaría de Programación para la Prevención de la Drogadicción y la Lucha contra el Narcotráfico, 2012). Although we did not detect any differences for those transgender or non-binary participants, the proportion of the sample who reported those gender categories was small, and thus, the statistical power (i.e. 15) insufficient to detect changes in consumption before and after the pandemic/lockdown.

Importantly, we found outstanding reductions in consumption among those up to 18 years old, and although not so high, also substantial reductions in all four alcohol consumption dimensions among emerging adults (19 to 24 years). Reductions diminished among older aged individuals. On one hand, older people might have maintained a Mediterranean pattern, typical for those groups in Argentina (Savic et al., 2016), while on the other, consumption among youth, characterized often by HED, may be more influenced by other social factors. Since in Argentina alcoholic beverages are mostly sold in supermarkets and food retails stores (Conde et al., $\mathrm{n} / \mathrm{d}$ ), considered essential business and thus open through the lockdown measures, our findings suggest that youth drinking is highly related to the social context. Previous studies indicate that it is in on-premises outlets mostly, where alcohol is sold to and consumed by adolescents and young adults (Conde et al., n/d). Even more, our findings suggest that restricting access to alcohol (either through on or off-premises points of sale) would be an effective measure to reduce consumption and related problems among adolescents and young adults. Although there is a compelling list of evidence coming from the northern hemisphere (Popova et al., 2009), evidence in this regard is still scarce in LAC (Conde et al., n/d), and findings presented here are a valuable contribution in that direction.

Our results reveal that those who suffered a decrease in income due to the pandemic and/or lockdown acknowledged even higher reductions in all consumption measures and alcohol related problems. These findings are in agreement with the international evidence which indicates that limiting the physical availability of alcoholic beverages through rising prices (Monteiro, 2016; Xin Xu et al., 2011), and the national evidence which shows a price elasticity for alcoholic beverages of around 6\% (Bardach et al., 2019). Taken together, these last results suggest that measures that restrict the physical availability of alcoholic beverages would be successful to limit consumption and its associated toll on death and disease among young persons. 
Results presented here also have policy implications beyond those strictly applied to alcoholic beverages (such as price increases and limiting the number of points of sale). Nations have taken different approaches to cope with the pandemic, and they could be roughly classified as either liberal, protecting economies and imposing few restrictions on social mobility and distancing (such as Brazil) (The Lancet, 2020b), or prioritizing collective health and thus, putting restrictive lockdown measures on place (such as Argentina) (Gemelli, 2020). Since the pandemic is a global stressor itself and the economic crisis that follows is an additional one, many detractors of the more restrictive isolation measures have argued that the toll in mental health could cause an escalation of substance consumption and problems. However, as some have predicted (Rehm et al., 2020) our findings indicate the contrary. Despite the stressful events and the possible anxiety arising from social isolation itself, restricted access (either through the closing of on-premises business or through lowered income) resulted in a decrease of consumption and related problems, and social distancing greatly diminished drinking and its negative consequences.

The present findings, must, however, be interpreted with caution and some limitations should be noted. First of all, we cannot preclude a self-selection bias due to the non-probabilistic nature of the sample. The larger proportion of women found in the sample might be a result of this bias, as women are more likely to answer online surveys (Conde \& Cremonte, 2015). Thus, generalizing these results merits careful attention. A second limitation pertains to self-reported data. Although usually employed in the alcohol field, and while the instruments and data collection procedures have been used successfully before (Conde \& Cremonte, 2015), some bias, such as recall bias could have affected the information obtained. Additionally, this was a cross-sectional study and a seasonal effect (i.e. consumption could have decreased due to seasonal fluctuations) could have affected the results. Last, the statistical power in same groups underrepresented in our sample (namely participants transgender/non-binary gender, or older than 61 years) was low, and thus, more research in these groups is needed. Future studies should expand the number of participants and their sociodemographic composition and evaluate changes while the pandemic progresses. Information from other sources, such as alcoholic beverages sales volume before and after the pandemic, could further complement selfreported data.

Despite those limitations, this is, to the best of our knowledge, the first report of changes in alcohol consumption and related problems in a Latin American country, before 
and after the COVID-19 pandemic. As such, our findings shed light on the impact of the COVID-19 pandemic and the isolation measures put in place to deter it, on alcohol drinking and its consequences. They indicate clearly, and in agreement with other international evidence, that two alcohol policies, namely price increases, and physical restrictions could be effective to avoid youth drinking and related problems.

This study takes advantage of the current exceptional circumstances to bring forward information for decision making once the pandemic is concluded. Findings clarify the value of measures aimed at reducing youth acquisition of alcoholic beverages by modifying their physical and social contexts. They also emphasize the power of city level authorities to put in place and enforce policies that reduce youth exposure to alcohol consumption. Nighttime policies, control of sales to minors, reduction of sale outlets, promotion of environments and alcohol-free events should be prioritized for the protection of young people. 


\section{References}

Ahmed, M. Z., Ahmed, O., Aibao, Z., Hanbin, S., Siyu, L., \& Ahmad, A. (2020). Epidemic of COVID-19 in China and associated psychological problems. Asian Journal of Psychiatry, 51, 102092. https://doi.org/10.1016/j.ajp.2020.102092

Babor, T. F., Higgins-Biddle, J. C., Saunders, J. B., \& Monteiro, M. G. (2001). The Alcohol Use Disorders Identification Test. Guidelines for use in Primary Care. Geneva: World Health Organization. Retrieved from: https://www.paho.org/hq/dmdocuments/2009/AUDIT_spa.pdf

Bardach, A., Ciapponi, A., Pizarro, M. E., Ríos, B., Palacios, A., Espínola, N., ... \& Cremonte, M. (2019). Caracterización de aspectos económicos, jurídicolegales y epidemiológicos útiles para impulsar una agenda pública orientada a disminuir el consumo de alcohol en Argentina. Revista Argentina de Salud Pública, 8-15. Retrieved from: http://rasp.msal.gov.ar/rasp/articulos/volumen38/8-15.pdf

Chodkiewicz, J., Talarowska, M., Miniszewska, J., Nawrocka, N., \& Bilinski, P. (2020). Alcohol Consumption Reported during the COVID-19 Pandemic: The Initial Stage. International journal of environmental research and public health, 17(13), 4677. https://doi.org/10.3390/ijerph17134677

Conde, K., Brandariz, R. A., \& Cremonte, M. (2016). Problemas por uso de alcohol en estudiantes secundarios y universitarios. Revista Chilena De NeuroPsiquiatría, 54(2), 84-93. http://dx.doi.org/10.4067/S0717$\underline{92272016000200002}$

Conde, K., \& Cremonte, M. (2015). Calidad de los datos de encuestas sobre consumo de alcohol en estudiantes universitarios Data Quality in Surveys on Alcohol Consumption among University Students. Cadernos de Saúde Pública, 31(1), 39-47. https://doi.org/10.1590/0102-311X00061114.

Conde, K., Nesoff, E. D., Peltzer, R. I., \& Cremonte, M. (n/d). Multilevel Model of Alcohol Outlet Density, Individual Characteristics and Alcohol-Related Injury in Argentinean Young Adults. Canadian Journal of Addiction (Accepted 7/2020).

Cremonte, M., Ledesma, R. D., Cherpitel, C. J., \& Borges, G. (2010). Psychometric properties of alcohol screening tests in the emergency department in Argentina, Mexico and the United States. Addictive Behaviors, 35(9), 818825. https://doi.org/10.1016/j.addbeh.2010.03.021

Cremonte, M., Cherpitel, C. J., Borges, G., Peltzer, R. I., \& Santángelo, P. R. (2010). Drinking patterns and DSM-IV alcohol use disorders' criteria in argentinean emergency department patients. Journal of drug addiction, education, and eradication, 6(3), 209-220.

Dumas, T. M., Ellis, W., \& Litt, D. M. (2020). What Does Adolescent Substance Use Look Like During the COVID-19 Pandemic? Examining Changes in Frequency, Social Contexts, and Pandemic-Related Predictors. The Journal of adolescent health: official publication of the Society for Adolescent Medicine, 67(3), 354-361. https://doi.org/10.1016/j.jadohealth.2020.06.018

Dyer, O. (2020). Covid-19 hot spots appear across Latin America. BMJ (Clinical research ed.), 369, m2182. https://doi.org/10.1136/bmj.m2182

Erol, A., \& Karpyak, V. M. (2015). Sex and gender-related differences in alcohol use and its consequences: Contemporary knowledge and future research 
considerations. Drug and Alcohol Dependence, 156, 1-13. https://doi.org/10.1016/j.drugalcdep.2015.08.023

García-Álvarez, L., de la Fuente-Tomás, L., Sáiz, P. A., García-Portilla, M. P., \& Bobes, J. (2020). ¿Se observarán cambios en el consumo de alcohol y tabaco durante el confinamiento por COVID-19? Adicciones, 32(2), 85-89.

Gemelli, N. A. (2020). Management of COVID-19 outbreak in Argentina: The beginning. Disaster Medicine and Public Health Preparedness, 1-3. https://doi.org/10.1017/dmp.2020.116

IBM Corp. (2010). IBM SPSS Statistics for Windows (Version 19.0). Armonk, NY: IBM Corp.

Johnson, E. C., Sanchez-Roige, S., Acion, L., Adams, M. J., Bucholz, K. K., Chan, G., . . Edenberg, H. J. (2020). Polygenic contributions to alcohol use and alcohol use disorders across population-based and clinically ascertained samples. Psychological Medicine, 1-10. https://doi.org/10.1017/S0033291719004045

Ministerio de Salud de la Nación. (2019). Diagnóstico de situación sobre el consumo de alcohol en Argentina y recomendaciones para la puesta en marcha de políticas sanitarias. Retrieved from: http://www.msal.gob.ar/images/stories/bes/graficos/0000001747cntconsumo_alcohol_argentina-11-2019.pdf

Ministerio de Salud de la Nación. (2020a). Situación de COVID-19 en argentina. (Reporte diario No. 16). Argentina: Retrieved from https://www.argentina.gob.ar/coronavirus/informesdiarios/reportes/marzo2020

Ministerio de Salud de la Nación. (2020b). Nuevo coronavirus COVID-19: Fases de administración del aislamiento. Argentina: Retrieved from https://www.argentina.gob.ar/coronavirus/aislamiento/fases

Ministerio de Salud de la Nación. (2020c). Situación de COVID-19 en argentina. (Reporte diario No. 260). Argentina: Retrieved from https://www.argentina.gob.ar/coronavirus/informesdiarios/reportes/julio2020

Monteiro, M. G. (2016). Public policies to prevent alcohol-related harm. Epidemiologia e_Serviços de Saúde, 25, 171-174. https://doi.org/10.5123/S1679-49742016000100017

Piontek, D., Kraus, L., \& Rist, F. (2013). Social contexts and the occurrence of episodic heavy drinking. The International Journal of Alcohol and Drug Research, 2(2), 45-52. https://doi.org/10.7895/ijadr.v2i2.106

Popova, S., Giesbrecht, N., Bekmuradov, D., \& Patra, J. (2009). Hours and days of sale and density of alcohol outlets: Impacts on alcohol consumption and damage: A systematic review. Alcohol \& Alcoholism, 44(5), 500-516. https://doi.org/10.1093/alcalc/agp054

Quinn, P. D., \& Fromme, K. (2012). Event-level associations between objective and subjective alcohol intoxication and driving after drinking across the college years. Psychology of Addictive Behaviors, 26(3), 384. https://doi.org/10.1037/a0024275

Rehm, J., Kilian, C., Ferreira- Borges, C., Jernigan, D., Monteiro, M., Parry, C. D., . . Manthey, J. (2020). Alcohol use in times of the COVID 19: Implications for monitoring and policy. Drug and Alcohol Review, 39(4). https://doi.org/10.1111/dar.13074 
Rodriguez, L. M., Litt, D. M., \& Stewart, S. H. (2020). Drinking to cope with the pandemic: The unique associations of COVID-19-related perceived threat and psychological distress to drinking behaviors in American men and women. Addictive Behaviors, 110, 106532. https://doi.org/10.1016/j.addbeh.2020.106532

Saengow, U., Assanangkornchai, S., \& Casswell, S. (2020). Alcohol: A probable risk factor of COVID-19 severity. Addiction (Abingdon, England), 10.1111/add.15194. Advance online publication. https://doi.org/10.1111/add.15194

Savic, M., Room, R., Mugavin, J., Pennay, A., \& Livingston, M. (2016). Defining "drinking culture": A critical review of its meaning and connotation in social research on alcohol problems. Drugs: Education, Prevention and Policy, 23(4), 270-282. https://doi.org/10.3109/09687637.2016.1153602

Secretaría de Programación para la Prevención de la Drogadicción y la Lucha contra el Narcotráfico (2012). La situación epidemiológica en Argentina al 2012. Retrieved from: http://observatorio.gob.ar/media/k2/attachments/poblacionZgeneral.pdf

Schuckit, M. A. (2009). Alcohol-use disorders. The Lancet, 373(9662), 492-501. https://doi.org/10.1016/S0140-6736(09)60009-X

Stanton, R., To, Q. G., Khalesi, S., Williams, S. L., Alley, S. J., Thwaite, T. L., Fenning, A. S., \& Vandelanotte, C. (2020). Depression, Anxiety and Stress during COVID-19: Associations with Changes in Physical Activity, Sleep, Tobacco and Alcohol Use in Australian Adults. International journal of environmental research and public health, 17(11), 4065. https://doi.org/10.3390/ijerph17114065

Szabo, G., \& Saha, B. (2015). Alcohol's effect on host defense. Alcohol research: current reviews, 37(2), 159. Retrieved from: https://www.arcr.niaaa.nih.gov/arcr372/article01.pdf

The Lancet (2020a). Drinking alone: COVID-19, lockdown, and alcohol-related harm. The Lancet Gastroenterology \& Hepatology, 5(7), 625. https://doi.org/10.1016/S2468-1253(20)30159-X

The Lancet (2020b). COVID-19 in Brazil: "so what?". The Lancet, 395(10235), 1461. https://doi.org/10.1016/S0140-6736(20)31095-3

Testino, G. (2020). Are patients with alcohol use disorders at increased risk for Covid-19 infection? Alcohol and Alcoholism, 55(4), 344-346. https://doi.org/10.1093/alcalc/agaa037

Thakur, L., Kojicic, M., Thakur, S. J., Pieper, M. S., Kashyap, R., Trillo-Alvarez, C. A., ... \& Gajic, O. (2009). Alcohol consumption and development of acute respiratory distress syndrome: a population-based study. International journal of environmental research and public health, 6(9), 2426-2435. https://doi.org/10.3390/ijerph6092426

Wardell, J. D., Kempe, T., Rapinda, K. K., Single, A., Bilevicius, E., Frohlich, J. R., Hendershot, C. S., \& Keough, M. T. (2020). Drinking to Cope During COVID-19 Pandemic: The Role of External and Internal Factors in Coping Motive Pathways to Alcohol Use, Solitary Drinking, and Alcohol Problems. Alcoholism, clinical and experimental research, 44(10), 2073-2083. https://doi.org/10.1111/acer.1442

World Health Organization. (2019). Global status report on alcohol and health 2018. World Health Organization. Retrieved from: 
https://apps.who.int/iris/bitstream/handle/10665/274603/9789241565639eng.pdf

Xu, X., \& Chaloupka, F. J. (2011). The effects of prices on alcohol use and its consequences. Alcohol Research \& Health, 34(2), 236. Retrieved from: https://www.ncbi.nlm.nih.gov/pmc/articles/PMC3860576/pdf/arh-34-2236.pdf

Received: 2020-09-21

Accepted: 2021-03-19 